\title{
CORRESPONDENCE
}

\section{Patent share-out}

$\mathrm{S}_{\mathrm{IR}}$ - There is an important omission in your reports (Nature 13 August, p.573) on the patents applied for by Stanford and the University of California at San Francisco, based on the work of Cohen and Boyer. The provisions in the patent are an advance over the previous manifestations of the academicbioindustrial complex, but there is no consideration of the nature of scientific research.

Scientific research is the outstanding example of an endeavour in which the end result by one group of scientists at any one time is the culmination of previous research and papers by many others.

What then is patentable? Is it (1) the result which lends itself to commercial exploitation, or is it (2) all the previous results along that line of inquiry? Under patent law, the two universities can obtain a patent under (1). I maintain that the basic ethos of the scientific community requires that the patent should include (2) - all the previous work and the scientists who did the work. So why should the two universities concerned be sole beneficiaries of the patent when, without the other research going on in that same line of inquiry at other institutions, Cohen and Boyer would never have been able to do their work?

The monetary gains for the patent (if any) should not benefit only the two universities but the whole scientific community. What I therefore suggest is that a universities research fund be set up, by all the institutions at which broadly-based biological research is going on. The administrators of the fund could set the ground rules for membership and for the allocation of monies gained through members' research activities between member institutions.

Only in this way can we preserve that peculiar institution, science, in which the whole is greater than the sum of its parts; in which all labour, or should labour, for the glory of the whole; in which the resultant scientific knowledge, not money, nor personal glory, is the ultimate goal, an institution which has become the hallmark of Western culture and which reflects the yet unknown capabilities of the mind of man.

Philip SiekeVitz Rockefeller University, New York, USA

\section{Anti-anti-"racism"?}

SIR - I certainly do not want to ascribe to Professor Rose, or anyone else, views that they do not hold, and would like to apologize to him if I have done so. But there is now, I think, a serious possibility of clearing the air. As Professor Rose (Nature 23 July, p.286) apparently does not subscribe to the opinion that, within the context of the sociobiology debate, there are no significant genetic differences from place to place within our species (and by implication, that there are no behavioural genetic differences between individuals), then perhaps he would be willing to say that there might be such differences. Since nobody in their right mind would call Professor Rose a racist, a statement of this kind from him would have the beneficial effect of lowering the temperature in the scientific debating chamber.

\section{Consider, please}

SIR - It is a noticeable and frequent occurrence at conferences that many people arrive late, enter or leave in the middle of presentations, or depart early, frequently with considerable insensitivity to the speakers and others attending the sessions. The practice is prevalent at conferences with simultaneous (often asynchronous) sessions and is possibly on the increase, though observations at the British Association meeting in York recently preclude the conclusion that the young are responsible; the lead was disquietingly apparent from oider generations at the BA meeting, and gives cause to doubt some of the hopes for the future of the BA that you expressed in your editorial (Nature 3 September, p.1.)

Is it not time for individuals and conference organizers to work towards some behavioural conventions bearing in mind, though perhaps falling short of, that which prevents someone who is as little as five minutes late for Don Giovanni from seeing the entire first act?

University of York, UK

\section{Professor Neurath}

SIR - Your article "German cancer research: Politics ousts science' (Nature 20 August 1981, p.665) is beset with so many inaccuracies and misrepresents the situation in such a deplorable manner that I must ask you to publish the following rebuttal:

(1) It is incorrect to state that I was previously Professor of Biochemistry at the University of Washington and that I have "only been scientific advisor to the University of Seattle". I was in fact founding chairman of the Department of Biochemistry of the University of Washington, from 1950 until my administrative retirement in 1975, and thereafter I have been Professor of Biochemistry and Associate Director for Scientific Affairs of the Fred Hutchinson Cancer Research Center in Seattle, one of the recognized 21 comprehensive cancer centers in the United States. Your cursory and pejorative description of my professional career reveals a bias which characterizes much of the remainder of your report.

(2) It is incorrect to say that the other directors of the institutes of the German Cancer Research Center were not consulted about my appointment. Rather, my appointment was approved by the

Wissenschaftlicher Rat (the internal scientific advisory board) to whom all 8 institute directors belong as voting members, and the Kuratorium (board of trustees), following the statutory process of appoinment.

(3) It is not true that the institute pays for my villa. In fact I am paying rent for use of a house which the German Cancer Research Center, with financial aid from a private philanthropic foundation, has rented for that purpose. Finally, although the annual budget of the German Cancer Research Center has been correctly quoted as approximately DM79 million, this sum cannot, even under the most extreme imaginable exchange rates, be equated with $\$ 1,817$ million, as stated in your report.

Your entire article represents such shoddy reporting that these inaccuracies alone, including the misquoted name of the Ministry
Director Dr Wolfgang Finke, should convince even the least informed reader of Nature of the bias and lack of credibility of this report. H. NeURATH

German Cancer Research Center. Heidelberg, FRG

SIR - Your note on German cancer research "Politics ousts science"' (Nature 20 August, p.665) contains some erroneous statements which I should like to correct:

(1) The German Cancer Research Center in Heidelberg is not "centrally administered by the Bundesministerium für Forschung und Technologie (BMFT)"', but is an independent public foundation according to the laws of the federal state of Baden-Württemberg. It has its own board of directors; a Kuratorium serves as supervisory body; scientific advice is given by an external committee with 12 members and an internal committee with 16 members. However, 90 per cent of the financial contributions to cover the costs of the centre's regular investments and operations are provided for by the BMFT, the remaining 10 per cent come from the federal state of BadenWürttemberg. The federal and state governments together have a veto power only in financial but not in scientific matters.

(2) Professor Neurath was unanimously elected as chairman and scientific member of the board of directors by the Kuratorium in December 1979 after he had been placed at the top of a list of three candidates by the internal scientific advisory committee with 10 of its 16 votes (which include all the directors of the eight institutes of the centre).

(3) Professor Neurath, before coming to Heidelberg, had not only been professor of biochemistry at the University of Washington in Seattle but also director for research (not "only advisor") at the Fred Hutchinson Cancer Research Center there. He had never "demanded that the institute pay for a villa" and his annual salary was not DM 167,000 but considerably less.

(4) Professor Neurath did not reject the multidisciplinary, clinically oriented approach of the centre and he did not, with my alleged support (my name being misspelled in your article), propose "to cut back on activities such as nuclear medicine and chemotherapy". What he proposed was in the long run to concentrate more on research both fundamental and clinically oriented and to reduce the centre's activities in routine work (there were no less than 17,000 cases of patient treatment, mostly diagnosis, in one year in the institute of nuclear medicine alone) by gradually shifting them to other institutions, especially to clinics of the region.

(5) In view of the present situation at the centre the Bundesminister für Forschung und Technologie Dr von Bulow and the Minister für Wissenschaft und Kunst (Land BadenWürttemberg) Professor Engler asked a number of internationally renowned scientists for advice on the future of the centre in order not to oust science there or replace it more and more by routine work but to bring it to full fruition. WOLFGANG FINKE

Kuratorium des $D K F Z$, BMFT, Bonn, FRG

WE accept that our report of Professor Neurath's resignation from the German Cancer Research Center was inaccurate in the respects he lists, and apologize to him and his colleagues for the distress they may have caused - Editor, Nature. 